\title{
Microstructure and Mechanical Properties of Multilayered Cu/Ti Composites Fabricated by Accumulative Roll Bonding
}

\author{
S. Jiang ${ }^{1}$, N. Jia ${ }^{1, *}$, X.H. Zhou ${ }^{1}$, H. Zhang ${ }^{2}$, T. $\mathrm{He}^{3}$ and X. Zhao ${ }^{1}$ \\ ${ }^{1}$ Key Laboratory for Anisotropy and Texture of Materials (Ministry of Education), School of Material Science and Engineering, \\ Northeastern University, Shenyang 110819, China \\ ${ }^{2}$ Key Laboratory of Electromagnetic Processing of Materials (Ministry of Education), Northeastern University, Shenyang 110819, China \\ ${ }^{3}$ Research Institute, Northeastern University, Shenyang 110004, China
}

Multilayered composites composed of pure copper and titanium $(\mathrm{Cu} / \mathrm{Ti})$ have been fabricated by accumulative roll bonding (ARB). The macroscopic lamellar structures, mechanical properties and microstructures of the composites are investigated. The results show that the $\mathrm{Cu}$ and Ti layers are bonded well during the ARB processing. With the increasing number of ARB cycles, Ti layers start to neck, fracture and even segregate within the $\mathrm{Cu}$ matrix, which is attributed to the activation of shear bands that cut through the multiple metal layers. At larger ARB cycles, the distribution of small fragmentations of Ti inside the $\mathrm{Cu}$ matrix is more homogeneous, which is attributed to the fact that the outer surfaces of the previously processed composite are placed in the interior of the subsequent ARB stack. Tensile testing at room temperature shows that the yield strength and the ultimate strength of the composites increased mildly with the increasing ARB cycles, while the uniform elongation of the composites is retained. Microhardness tests reveal that the increase of strength in the composites during ARB mainly results from the reinforcement of the Ti layers. The mechanical behaviors of the composites can be attributed to the effect of the mixed microstructures in the both constituent metals. [doi:10.2320/matertrans.M2016307]

(Received September 2, 2016; Accepted November 9, 2016; Published December 9, 2016)

Keywords: copper/titanium multilayered composite, accumulative roll bonding, microstructure, mechanical properties

\section{Introduction}

Metallic multilayered composites (MMCs) belong to a new class of materials where alternative thin layers of metals are combined into a single structural unit to improve a diversity of properties ${ }^{1-3)}$. Metallic multilayered materials produced from dissimilar metals combine the unique advantages of the constituent metals and show better properties than the individual metals. Multilayered materials can be produced by bottom-up processes like electro deposition ${ }^{4)}$, iron sputtering $^{5)}$, vapor deposition ${ }^{6)}$ and magnetron sputtering deposition. Unfortunately, these methods could not produce multilayers on a large scale and in significant quantities, which limits their potential application in industry. On the contrary, with the development of bulk forming techniques such as accumulative roll bonding (ARB), it is possible to produce multilayered materials with large dimensions ${ }^{1)}$. ARB processing has been used as a novel and applicable method for fabricating multilayered composites in a relatively simple and inexpensive manner ${ }^{7,8)}$. At the same time, ARB belongs to a severe plastic deformation (SPD) method. By introducing structural defects like dislocations into the deformed composites, it is capable of providing ultrafine grained microstructures for an ARBed bulk material ${ }^{9,10)}$.

During the ARB processing, with the increasing cycles the typical microstructure includes necking and fracturing of the hard phase. This phenomenon is related to the development of shear bands, as interface instability induced by large trans-interface shear tend to occur in the multilayered structures ${ }^{11-13)}$. The difference in mechanical properties between the constituent phases is the origin of this strain incompatibility at the hetero-interface. On the other hand, symmetric rolling can be simplified as a deformation mode of plane strain compres-

*Corresponding author, E-mail: jian@atm.neu.edu.cn sion. For a multilayered composite produced by ARB, as the soft phase is stretched more in the rolling direction than the hard phase, shear stress is generated between the neighboring phases. The shear stress acting on the surface of the hard phase then leads to the tension of the phase and makes it behave like under the tensile testing. When the shear stress exceeds the yield strength of the phase, necking takes place ${ }^{14)}$ and the plastic instability even results in fracture of the phase $^{15)}$.

It is well known that Titanium, with a hexagonal-closepacked (hcp) crystallographic structure, exhibits great potential as structural materials in many fields ${ }^{16,17)}$ due to its high strength, good fatigue performance, sufficient corrosion resistance and excellent biocompatibility ${ }^{18)}$. However, the formability of $\mathrm{Ti}$ is low because of its limited number of slip systems at ambient temperature ${ }^{19)}$. On the contrary, Copper, with a face-centered-cubic (fcc) structure, shows excellent formability as well as good thermal and electrical conductivities. However, the strength of $\mathrm{Cu}$ is low, as strengthening of metals is usually contradictory to the improvement of plastic stability and electrical conductivity. Therefore, it is anticipated that the multilayered $\mathrm{Cu} / \mathrm{Ti}$ composites produced via ARB technique could combine the above-mentioned advantages of the individual metals. At the same time, by introducing a large number of hetero-interfaces into the composite structure, many desired properties, such as high strength and plasticity, good corrosion resistance and radiation resistance could be obtained ${ }^{20-23)}$. Up to now, numerous studies on the $\mathrm{ARB}$ processed materials consisting of dissimilar metals have been conducted. Among those, the main focus is placed on the multilayered composites including fcc/fcc or fcc/bcc (bcc: body-centered-cubic) heterophase interfaces, such as $\mathrm{Cu} / \mathrm{Ag}^{4,12)}, \mathrm{Cu} / \mathrm{Al}^{3,24)}, \mathrm{Cu} / \mathrm{Nb}^{6,23,25)}$ and $\mathrm{Cu} / \mathrm{Ta}^{14)}$. However, the investigation on the hcp material systems is quite limited. Only the mechanical behaviors in $\mathrm{Mg} / \mathrm{Al}^{19,26)}$ and $\mathrm{Cu} / \mathrm{Zr}^{12,27)}$ 
composites are studied systematically.

In this work, we aim to study the inhomogeneous microstructure and deformation behavior of multilayered $\mathrm{Cu} / \mathrm{Ti}$ composites produced by ARB, which was rarely studied in previous studies. The layout of the paper is as follows: First, the lamellar structures and mechanical properties of the composites after different ARB cycles are presented. Then to explore micromechanisms that contribute to the deformation behaviors of the composites, microstructures of the respective metals after ARB are presented. Finally, the mechanical stability of the composites after annealing is evaluated.

\section{Experimental Procedures}

\subsection{ARB fabrication of $\mathrm{Cu} / \mathrm{Ti}$ composites}

The materials used for fabricating multilayered composites were two kinds of metal sheets, i.e. commercially available pure $\mathrm{Ti}(99.7$ mass \%) and pure $\mathrm{Cu}(99.9$ mass $\%)$ that were cut into the same dimension of $120 \mathrm{~mm}$ (length) $\times 50 \mathrm{~mm}$ (width) $\times 1 \mathrm{~mm}$ (thickness). In order to weaken the stress and primary textures, the $\mathrm{Ti}$ and $\mathrm{Cu}$ sheets were annealed at $700^{\circ} \mathrm{C}$ for $60 \mathrm{~min}$ and at $200^{\circ} \mathrm{C}$ for $20 \mathrm{~min}$ in a vacuum furnace, respectively. First, the surfaces of the metal sheets were degreased in acetone and wire brushed. Then, four pieces of $\mathrm{Cu}$ and three pieces of $\mathrm{Ti}$ sheets were mutually stacked with the sequence of $\mathrm{Cu} / \mathrm{Ti} / \mathrm{Cu} / \mathrm{Ti} / \mathrm{Cu} / \mathrm{Ti} / \mathrm{Cu}$. They were fastened tightly by aluminum rivets to produce a sandwich stack. The stack was pre-heated at $300^{\circ} \mathrm{C}$ for $20 \mathrm{~min}$ in a vacuum furnace and then subjected to warm roll bonding in a two high rolling mill with the rolling velocity of $1 \mathrm{~m} / \mathrm{min}$. The thickness reduction was $65 \%$ in the rolling pass. Subsequently, the rolled composite was annealed at $500^{\circ} \mathrm{C}$ for $90 \mathrm{~min}$, in order to enhance the diffusion and postpone the occurrence of plastic instabilities ${ }^{7)}$. The composite was then cut into several pieces with the same area. After the above-mentioned preparation, i.e., degreasing and wire brushing of the contacting surfaces, the composites were stacked, pre-heated and subjected to the second roll bonding. The above intermediate annealing and roll bonding treatments were repeated three times and a thickness reduction of $65 \%$ was maintained for each cycle. Table 1 shows the total number of metal layers after each ARB cycle, the corresponding nominal layer thickness $h$, and the corresponding equivalent true strain $e$. $e$ is calculated as $e=$ $\frac{2}{\sqrt{3}} \ln \left(h_{0} / h\right)$, where $h_{0}$ is the initial layer thickness. It should be mentioned that the $\mathrm{Cu}$-Ti bonding was created only during the first ARB cycle, and all the subsequent bonding steps only involved the bonding of $\mathrm{Cu}$ on $\mathrm{Cu}$.

Table 1 Variation of the number of layers, the nominal thickness of single layer and the total strain with the increasing ARB cycles.

\begin{tabular}{cccc}
\hline $\begin{array}{c}\text { Number of } \\
\text { ARB cycles }\end{array}$ & $\begin{array}{l}\text { Number of } \\
\text { layers }\end{array}$ & $\begin{array}{c}\text { Nominal thickness of } \\
\text { a single layer }(h, \mu \mathrm{m})\end{array}$ & $\begin{array}{l}\text { Equivalent true } \\
\text { strain }(e)\end{array}$ \\
\hline 1 & 7 & 333 & 1.27 \\
2 & 14 & 110.89 & 2.53 \\
3 & 42 & 36.93 & 3.81 \\
4 & 126 & 12.30 & 5.08 \\
\hline
\end{tabular}

\subsection{Microstructural characterization}

To characterize the multilayered morphology of the $\mathrm{Cu} / \mathrm{Ti}$ composites, the rolling direction-normal direction (RD-ND) sections of the ARB processed specimens were observed by field emission scanning electron microscope (SEM, JEOL JSM-7001F) with the back-scattering mode. The samples were prepared by grinding and mechanical polishing. The microstructural characterization of $\mathrm{Cu}$ and Ti layers in the composite after the fourth ARB cycle was carried out by transmission electron microscopy (TEM) at $200 \mathrm{kV}$ (Tecnai $\mathrm{G}^{2} 20$, FEI). The selected sections for TEM observation were parallel to the rolling plane and all areas were close to the middle-thickness of the composite. The thin foils were prepared by twin-jet electro-polishing in a solution consisting of nitric acid $\left(\mathrm{HNO}_{3}\right)$ and methanol $\left(\mathrm{CH}_{3} \mathrm{OH}\right)$ with a volume ratio of $3: 17$.

XRD measurements were carried out on the rolling plane of the ARB processed sheets to identify the phase composition. The scans were performed by an X-ray diffractometer (XRD, Smartlab, Rigaku) operated at $40 \mathrm{kV}$ and $200 \mathrm{~mA}$ using $\mathrm{Cu} \mathrm{K} \alpha$ radiation with a wavelength of $0.1544 \mathrm{~nm}$. The measurements were conducted over a $2 \theta$ scanning range from $35^{\circ}$ to $100^{\circ}$ using a step size of $0.02^{\circ}$ and a counting time of $4 \mathrm{~s}$ per step.

\subsection{Mechanical properties}

The mechanical properties of the $\mathrm{Cu} / \mathrm{Ti}$ multilayers were evaluated by performing tensile tests and hardness measurements. The tensile samples were machined into dog-boned shape with the tensile direction parallel to RD. The gauge length and width were $13 \mathrm{~mm}$ and $3 \mathrm{~mm}$, respectively. The tensile tests were performed at room temperature (RT) on the AG-Xplus $100 \mathrm{kN}$ testing machine with a nominal strain rate of $10^{-3} \mathrm{~s}^{-1}$. The microhardness was measured on the longitudinal section (RD-ND plane) of the ARB processed composites using a $401 \mathrm{MVD}^{\mathrm{TM}}$ digital sclerometer under an applied load of $50 \mathrm{~g}$ for $15 \mathrm{~s}$. In the middle-thickness of each composite, at least 15 measurements at different locations were taken for the individual metals, so as to obtain average microhardness values for both $\mathrm{Ti}$ and $\mathrm{Cu}$.

\section{Results and Discussion}

\subsection{Assessment of lamellar structures}

The SEM micrographs of $\mathrm{Cu} / \mathrm{Ti}$ composites after various ARB cycles are shown in Fig. 1. In all the samples, $\mathrm{Cu}$ and $\mathrm{Ti}$ layers are bonded well. Also, the $\mathrm{Cu}-\mathrm{Cu}$ interfaces introduced after the first cycle are rarely observed in the composites subjected to more ARB cycles, indicating the good interfacial bonding of the composites. After the first ARB cycle, curvature of the interfaces between phases has occurred (Fig. 1(a)). With increasing cycles, the thickness of both $\mathrm{Cu}$ and $\mathrm{Ti}$ decreases. After the second cycle, Ti layers are more severely curved to neck (Fig. 1(b)), fracture (Fig. 1(c)) and even segregate (Fig. 1(d)), as indicated by arrows in the figures. Considering the significant inhomogeneity of the deformed microstructure, it is difficult to quantify the average thickness for the respective metals. Thus only the nominal layer thickness after each ARB cycle is given, as listed in Table 1. Moreover, some lenticular nodules as a result of fragmentation and 


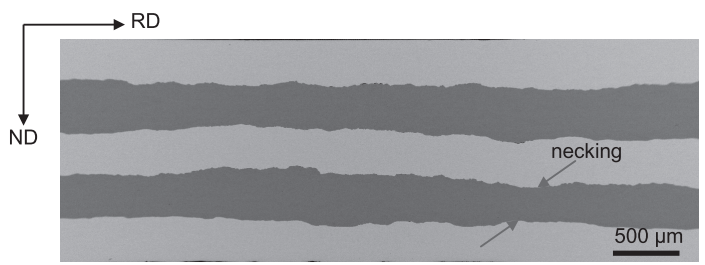

(a)

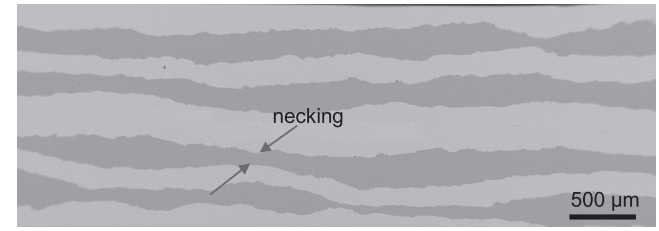

(b)

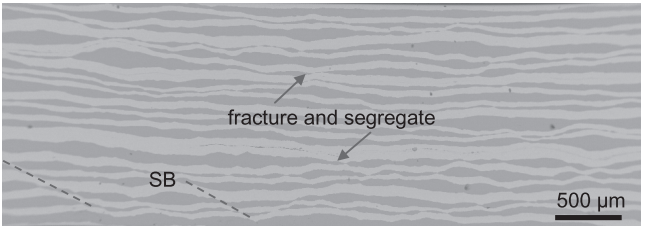

(c)

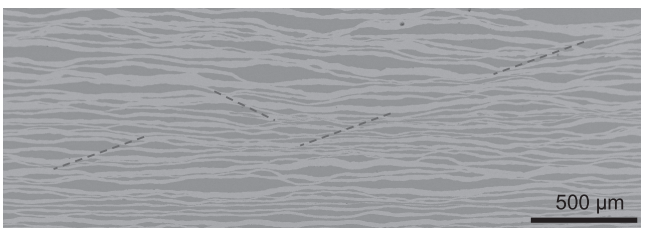

(d)

Fig. 1 SEM micrographs of longitudinal cross-section of ARB processed $\mathrm{Cu} / \mathrm{Ti}$ composites: (a) after 1 cycle, (b) after 2 cycles, (c) after 3 cycles and (d) after 4 cycles. The $\mathrm{Cu}$ phase appears bright and the Ti phase appears dark.

necking of Ti are produced in the microstructure, which is the most prominent feature in the ARB process. The occurrence of necking and discontinuity of the hard metal with relatively large strength and work hardening ability has also been reported for many other material systems ${ }^{28-32)}$, due to the formation of shear bands (shown by dashed lines) across the different metal layers during deformation. The thickness distribution of Ti layers along RD is inhomogeneous, whereas the thickness reduction of $\mathrm{Cu}$ layers is more homogeneous. In this case, the continuous $\mathrm{Cu}$ matrix acts as a transfer media of load from $\mathrm{Cu}$ to $\mathrm{Ti}$ and $\mathrm{Cu}$ fills up all spaces between the different Ti layers, which may be beneficial for the conductivity application ${ }^{1,33)}$. Generally, the plastic instability caused by the different flow properties of the constituent metals makes the hard phase (Ti) neck and finally rupture during the co-deformation of dissimilar metals ${ }^{3,7)}$, thus the soft phase $(\mathrm{Cu})$ preserves the coherency in most of the regions during the ARB processing. In Figs. 1(c) and (d), macroscopic shear bands that cut through several Ti layers can be clearly identified. The substantial necking in the Ti layers causes the $\mathrm{Cu}$ layers to shear approximately at an angle of $45^{\circ}$ to $\mathrm{RD}$, which has also been observed in $\mathrm{Al} / \mathrm{Zn}$ composites fabricated by $A R B^{28)}$. During the ARB processing, the soft $\mathrm{Cu}$ layers are stretched more severely along RD than the hard Ti layers. Therefore, significant shear stress is concentrated at the inter-

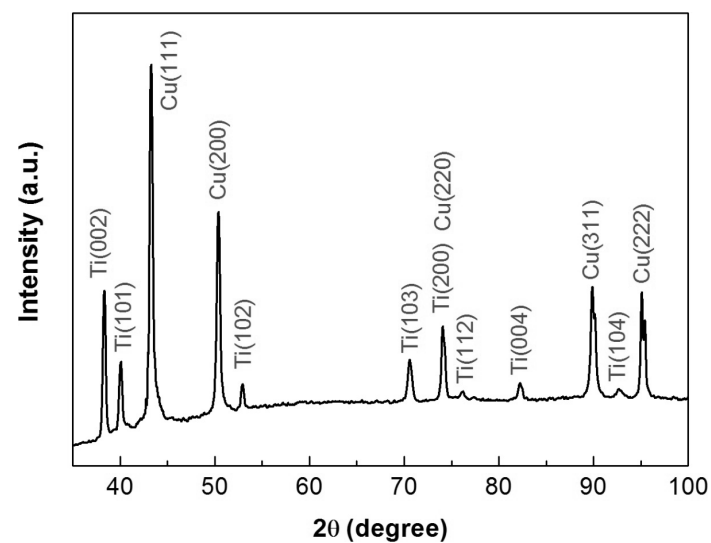

Fig. 2 XRD pattern of $\mathrm{Cu} / \mathrm{Ti}$ composite processed after four ARB cycles.

faces. The in-plane shear stress at the phase boundaries leads to the formation of shear bands in the $\mathrm{Cu}$ layers. Min et al. ${ }^{7}$ proposed that in a multilayered microstructure shear bands move into the hard layers due to their lower formability and the bands cause failure of the layers, which is consistent with the current observation. In addition, at larger ARB cycles the distribution of Ti layers in the form of small parts inside the $\mathrm{Cu}$ matrix is more dispersive inside the RD-ND plane, as shown in Fig. 1(d). This is attributed to the fact that the outer surfaces of the previously processed composite are placed in the interior of the subsequent ARB stack. The continuous transformation leads to a homogeneous internal structure, even though different macroscopic shear strains imposed by friction with the rollers are introduced into the different thicknesses. Figure 2 shows the XRD pattern of the $\mathrm{Cu} / \mathrm{Ti}$ composite fabricated by four ARB cycles. Only the peaks from titanium and copper phases are identified, indicating that at the phase boundaries only diffusion between the constituent metals occurs and no metallic phases are formed during the repeated rolling processing.

\subsection{Mechanical properties}

To study the effect of the number of ARB cycles on the tensile properties of the $\mathrm{Cu} / \mathrm{Ti}$ multilayers, uniaxial tensile tests along RD are conducted for the ARBed composites. Figure 3 shows the engineering stress-strain curves as well as the true stress-strain curves of the composites. The stress-strain curves of the starting annealed $\mathrm{Cu}$ and $\mathrm{Ti}$ sheets are also presented for comparison. It is shown that both yield strength and ultimate strength of the composites increase with elevated ARB cycle numbers. As mentioned in other studies ${ }^{7,26)}$, this is attributed to strain hardening and grain refinement of the constituent metals. After the fourth cycle, the maximum yield strength and tensile strength reach $325 \mathrm{MPa}$ and $395 \mathrm{MPa}$, respectively. The tensile strength of this sample is around 0.5 times higher than that of the primary copper, and is only slightly lower compared to the primary Ti. In the current study, grains within the $\mathrm{Cu}$ layers are fully recrystallized during the ARB process due to the high rolling temperature and interval reheating. Therefore, the increasing strength of the ARBed composite can be mainly attributed to the Ti layers. On the other hand, as the ARB cycle increases, the maximum elongation of the composite decreases gradually. This is 

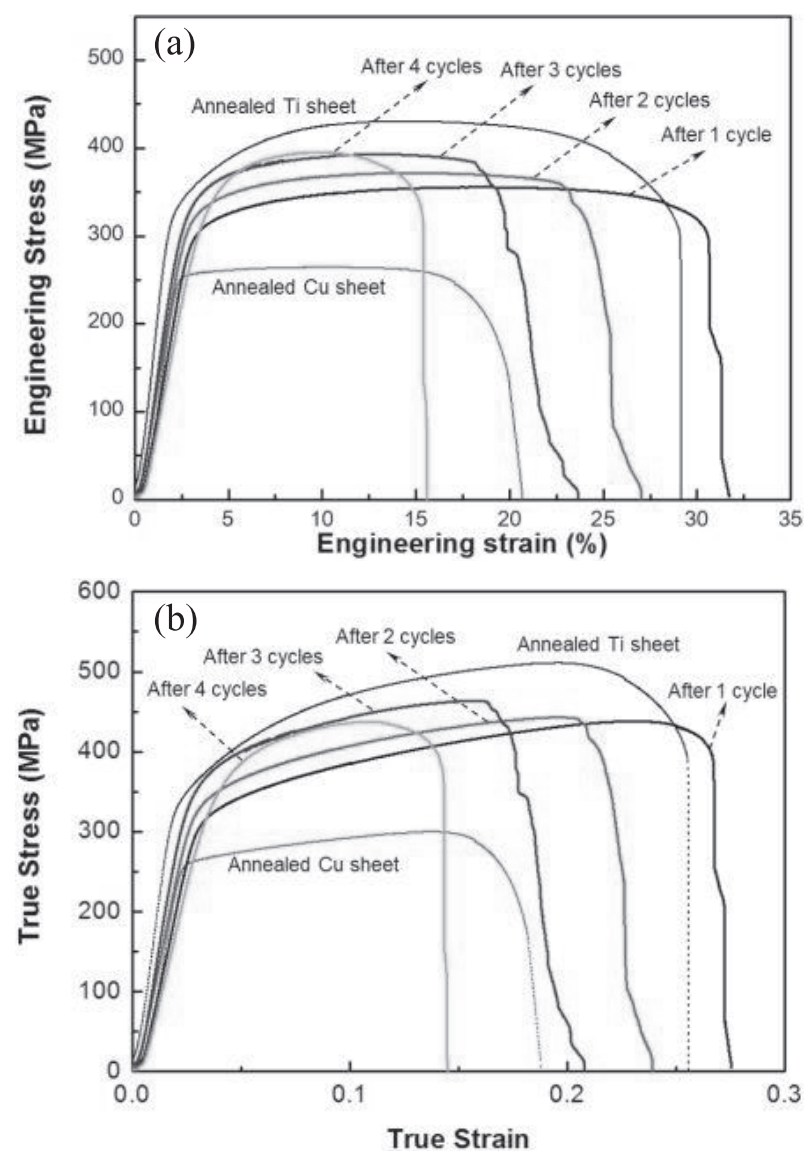

Fig. 3 Engineering stress-strain curves (a) and true stress-strain curves (b) for the annealed $\mathrm{Cu}$ and $\mathrm{Ti}$ and the $\mathrm{ARB}$ processed $\mathrm{Cu} / \mathrm{Ti}$ composites.

attributed to the limited dislocation mobility of the composites after more ARB cycles. However, the continuous elevation of the true stress with the true strain are observed for all the samples within the plastic deformation range (see Fig. 3(b)), indicating the certain work hardening ability of the studied lamellar composites. The maximum elongation among the studied ARBed composites is $31 \%$, a $55 \%$ rise from the starting pure copper. Microhardness variation of $\mathrm{Cu}$ and Ti layers at the middle-thickness of the ARBed composites is presented in Fig. 4. It is obvious that Ti shows a higher average hardness than $\mathrm{Cu}$ at different ARB cycles. For the 1 3 cycles, the hardness in Ti layers increases with increasing ARB numbers. During these cycles, strain hardening that is related to the enhanced dislocation density and interaction among the dislocations may lead to the increasing microhardness of Ti. For the composite after the fourth ARB cycle, however, the room temperature dynamic recovery can be enhanced in the microstructure with ultrafine grains, due to the creation of non-equilibrium, high-energy and unstable grain boundaries (high-angle grain boundaries) ${ }^{34}$ ). Thus dislocation annihilation during the indentation testing leads to a decreasing hardness of the Ti layers. During the whole period of $\mathrm{ARB}$, the hardness of $\mathrm{Cu}$ only shows a minor increase. This is because the $\mathrm{Cu}$ layers are fully recrystallized during the warm ARB processing as well as the intermediate annealing. This result is similar to the hardness variation of $\mathrm{Mg}$ layers found in $\mathrm{Mg} / \mathrm{Al}$ composites ${ }^{19)}$, which was also attributed to full recrystallization of the metal during the whole ARB processing.

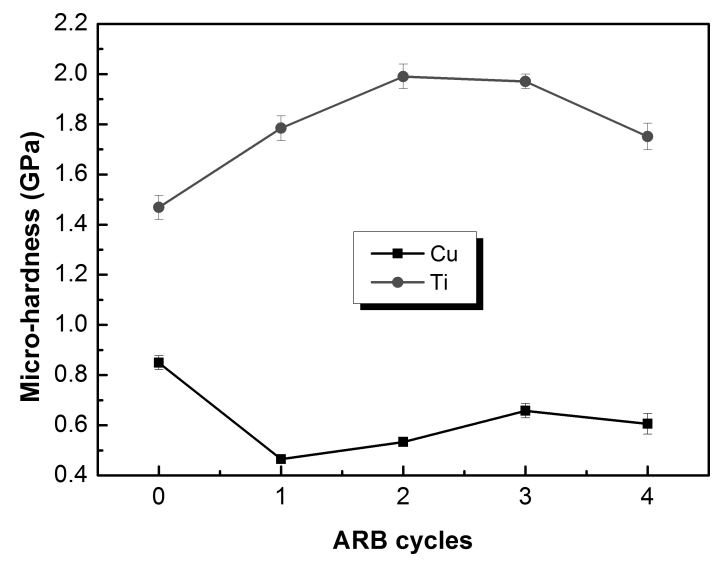

Fig. 4 Microhardness variation of individual $\mathrm{Cu}$ and $\mathrm{Ti}$ layers in the $\mathrm{Cu} / \mathrm{Ti}$ composites processed after different ARB cycles.

To this stage, it can be deduced that the increase of strength in the composites during the ARB processing mainly result from the reinforcement of the Ti layers.

It should be noted that the evolution of strength in the multilayered $\mathrm{Cu} / \mathrm{Ti}$ composites is different from that in most ARB processed materials by various cycles at room temperature ${ }^{19,35-37)}$. The literatures have shown that strength of the multilayers dramatically increases with increasing ARB cycle numbers, accompanied by the sharp decrease of uniform elongation. This is ascribed to the significant strain hardening as well as grain refinement of the constituent metals. However, in the current work, $\mathrm{Cu} / \mathrm{Ti}$ multilayers only show a mild increase of strength during ARB processing and at the same time the ductility of the multilayers is retained. The flow stress of the $\mathrm{Cu} / \mathrm{Ti}$ composites stands between that of the constituents, which agrees with the rule of mixture ${ }^{38,39)}$. The mechanical behaviors of the composites found here can be attributed to the microstructures formed during the applied $\mathrm{ARB}$ route, as will be shown in the next.

\subsection{Microstructures}

Figures 5-6 show the TEM microstructures of the $\mathrm{Cu} / \mathrm{Ti}$ composite processed after four cycles. Two characteristic morphologies are observed in the Ti layers: One is the microstructure with high densities of dislocation tangles/networks distributed in nearly equiaxed grains of $200 \mathrm{~nm}$ (Fig. 5(a)), i.e., a similar morphology observed in the room-temperature ARBed pure Ti by Terada et al. ${ }^{18)}$. Complicated ring-like diffraction pattern is found in the selected area, indicating that the area involves nano-sized crystallites with a variety of orientations. The other morphology is the sub-grain cells with a mean size less than $200 \mathrm{~nm}$ recovered from the dislocation structure (Fig. 5(b)). The selected area diffraction also shows a ring-like pattern composed of some specific orientations. Ti has a very low thermal conductivity $\left(17 \mathrm{~W} \mathrm{~m}^{-1} \mathrm{~K}^{-1}\right)^{18)}$ compared with $\mathrm{Cu}\left(376.8 \mathrm{~W} \mathrm{~m}^{-1} \mathrm{~K}^{-1}\right)$. Thus, the significantly low dislocation density within the sub-grain region of the Ti layers is assisted by the remarkable temperature increase in some local area with large strain, such as shear bands. For the $\mathrm{Cu}$ layers, some dislocations can still be identified (Fig. 6(a)). Whereas a considerable amount of annealing twins with prominent morphologies, such as step-shaped twins are clear- 


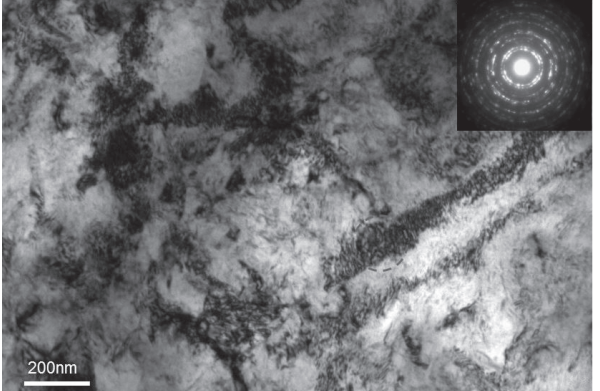

(a)

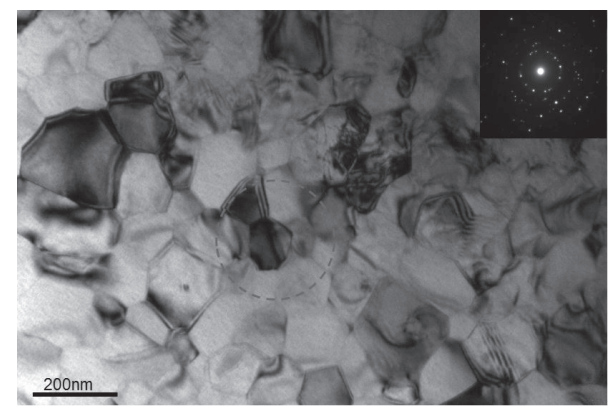

(b)

Fig. 5 Representative TEM images obtained from Ti layers of the $\mathrm{Cu} / \mathrm{Ti}$ composite processed by four ARB cycles. The inset shows diffraction pattern of the selected area.

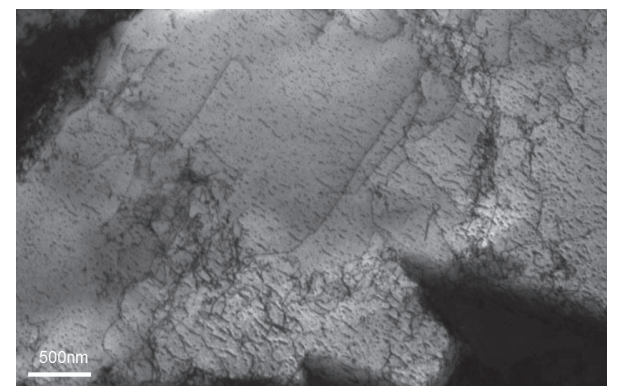

(a)

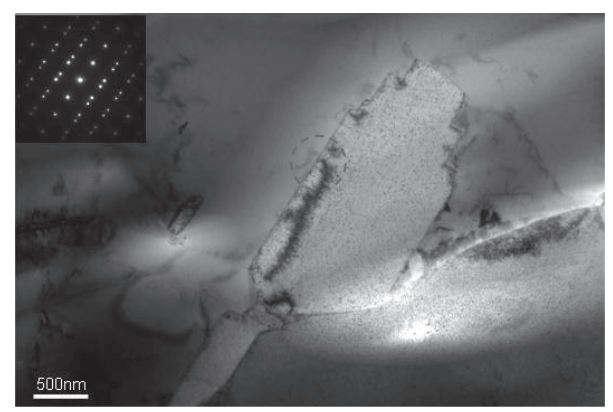

(b)

Fig. 6 Representative TEM images obtained from $\mathrm{Cu}$ layers of the $\mathrm{Cu} / \mathrm{Ti}$ composite processed by four ARB cycles. The inset shows the diffraction pattern for the selected area.

ly evident (Fig. 6(b)). This confirmed that recrystallization and even grain growth are the most important features for $\mathrm{Cu}$ when the composite is fabricated at $300^{\circ} \mathrm{C}$. The mixed microstructures in the both $\mathrm{Ti}$ and $\mathrm{Cu}$ contribute to the limited increase of strength and the retained ductility of the bulk com- posites during ARB.

ARB has been previously utilized for other material systems composed of at least one hep metal, such as $\mathrm{Ni}^{-\mathrm{Ti}^{5} \text {, }}$ $\mathrm{Al}-\mathrm{Mg}^{10,19,26)}$ and $\mathrm{Nb}-\mathrm{Zr}^{40)}$. According to those, ARB is usually carried out at temperatures lower than $0.5 T_{m}\left(T_{m}\right.$ : melting point), so as to prevent significant grain growth of the constituent metals. In this work, however, ARB is only an effective method to produce ultrafine grains in Ti but not in $\mathrm{Cu}$. The application of warm bonding is due to two facts. First, when ARB is performed at low rolling temperatures, bonding quality between the $\mathrm{Cu}$ and $\mathrm{Ti}$ layers would be poor; Second, for a co-deformed multilayered composite, as strain has to be accommodated between the adjacent phases, then strain localization in the form of shear banding tends to occur readily. In this case, if ARB is performed at an appropriate temperature where sufficient slip systems are activated in the constituent metals, shear banding can be suppressed and homogeneous deformation of each layer becomes possible. Therefore, the large thickness reduction of $65 \%$ together with the bonding temperature of $300^{\circ} \mathrm{C}$ applied here contribute to the both homogeneous lamellar structures and excellent interface bonding quality.

\subsection{Mechanical stability of the annealed composites}

Mechanical stability of the ARB processed $\mathrm{Cu} / \mathrm{Ti}$ lamellar multilayers after annealing is examined in this section. First, the one-cycle-ARBed composites are annealed at $300^{\circ} \mathrm{C}$, $500^{\circ} \mathrm{C}$ and $800^{\circ} \mathrm{C}$ for $60 \mathrm{~min}$, respectively, and then cooled in furnace. Subsequently, the annealed composites are cold rolled at room temperature to reach a total reduction of $50 \%$ in thickness. This reduction is achieved at an engineering strain of $10 \%$ in each pass of deformation. Figure 7 shows that after $50 \%$ cold rolling, cracks are absent at the $\mathrm{Cu}-\mathrm{Ti}$ interfaces in all the samples, indicating the good ductility of the constituent metals as well as the excellent bonding quality of hetero-interfaces. Compared with the composites without annealing and after annealing at $300^{\circ} \mathrm{C}$ (Figs. 7(b) and (d)), the cold rolled samples after annealing at $500^{\circ} \mathrm{C}$ and $800^{\circ} \mathrm{C}$ show the much flatter interfaces between $\mathrm{Cu}$ and Ti (Figs. 7(f) and (h)). For the sample annealed at $800^{\circ} \mathrm{C}$, a large number of massive intermetallic compound are observed at the $\mathrm{Cu}-\mathrm{Ti}$ interfaces, which makes the interfaces become blurry (Figs. 7(g) and (i)). After cold rolling, obvious cracks induced by the different deformation behaviors of the constituent metals appear on the compound (Figs. 7(h) and (j)). The energy dispersive spectroscopy (EDS) analysis confirms the formation of the intermetallic compound $\mathrm{CuTi}$ at the interfaces. However, this does not lead to the reduced interface bonding or prominent deterioration of mechanical properties for the composites. From the stress-strain curves obtained by room-temperature tensile testing for those annealed samples (Fig. 8), one can see that even though the composites have experienced high-temperature annealing up to $800^{\circ} \mathrm{C}$, high ductility and considerable strength are retained. Namely, all the composites after annealing exhibit the desired work hardening ability and thus homogeneous deformation after large cold rolling reductions. On the other hand, in contrast to the unannealed sample, necking and fracture of Ti layers are seldom found in the annealed composites during the subsequent cold rolling, and, the interfaces between the metals are more 


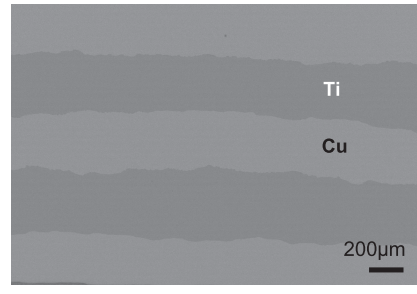

(a) Without annealing

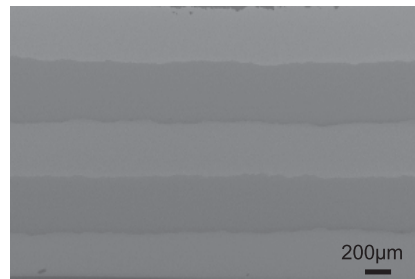

(c) Annealed at $300^{\circ} \mathrm{C}$

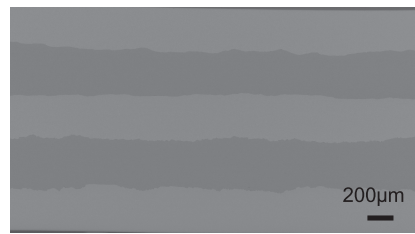

(e) Annealed at $500^{\circ} \mathrm{C}$

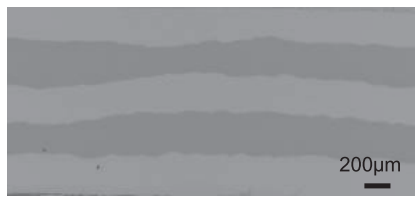

(g) Annealed at $800^{\circ} \mathrm{C}$

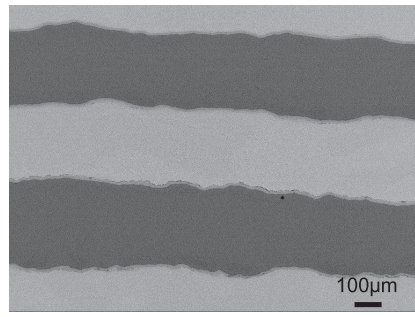

(i) Annealed at $800^{\circ} \mathrm{C}$

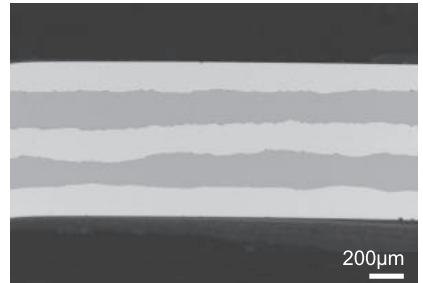

(b) Without annealing $+50 \%$ cold rolling

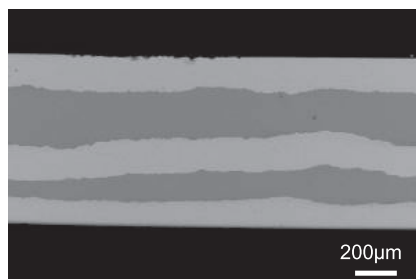

(d) Annealed at $300^{\circ} \mathrm{C}+50 \%$ cold rolling

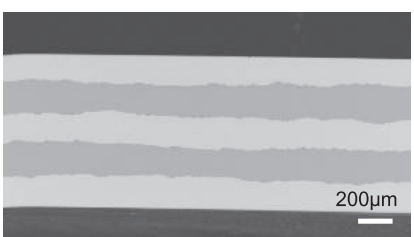

(f) Annealed at $500^{\circ} \mathrm{C}+50 \%$ cold rolling

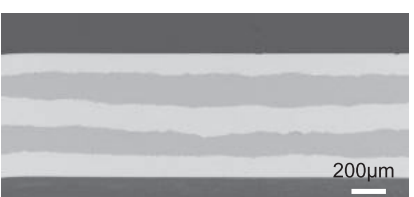

(h) Annealed at $800^{\circ} \mathrm{C}+50 \%$ cold rolling

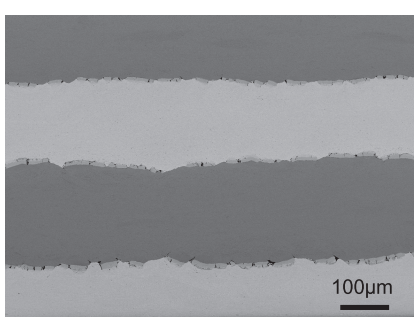

(j) Annealed at $800^{\circ} \mathrm{C}+50 \%$ cold rolling

Fig. 7 SEM micrographs of the $\mathrm{Cu} / \mathrm{Ti}$ composites processed by one ARB cycle and the subsequent annealing and 50\% cold rolling: (a)-(b) without annealing, (c)-(d) annealed at $300^{\circ} \mathrm{C}$, (e)-(f) annealed at $500^{\circ} \mathrm{C}$, and (g) (h) annealed at $800^{\circ} \mathrm{C}$. Figs. (i) and (j) are micrographs with higher magnifications correspond to $(\mathrm{g})$ and $(\mathrm{h})$, respectively.

flat. In other words, shear banding that would prevail within the microstructures after large rolling reductions is suppressed in the subsequently heat-treated samples. The similar observation has also been reported in a recent work by Ardeljan et ll. $^{40)}$. This validates the importance of applying intermediate annealing between the contiguous ARB cycles in this work $\left(500^{\circ} \mathrm{C}\right.$ for $\left.90 \mathrm{~min}\right)$. So we can conclude that for the annealed composites, during the process of the subsequent cold deformation the constituent metal layers undergo a more homogeneous thickness reduction along ND than the unannealed ones, so that the former can maintain the both high strength and good ductility.

\section{Conclusions}

In the present work, multilayered $\mathrm{Cu} / \mathrm{Ti}$ composites were
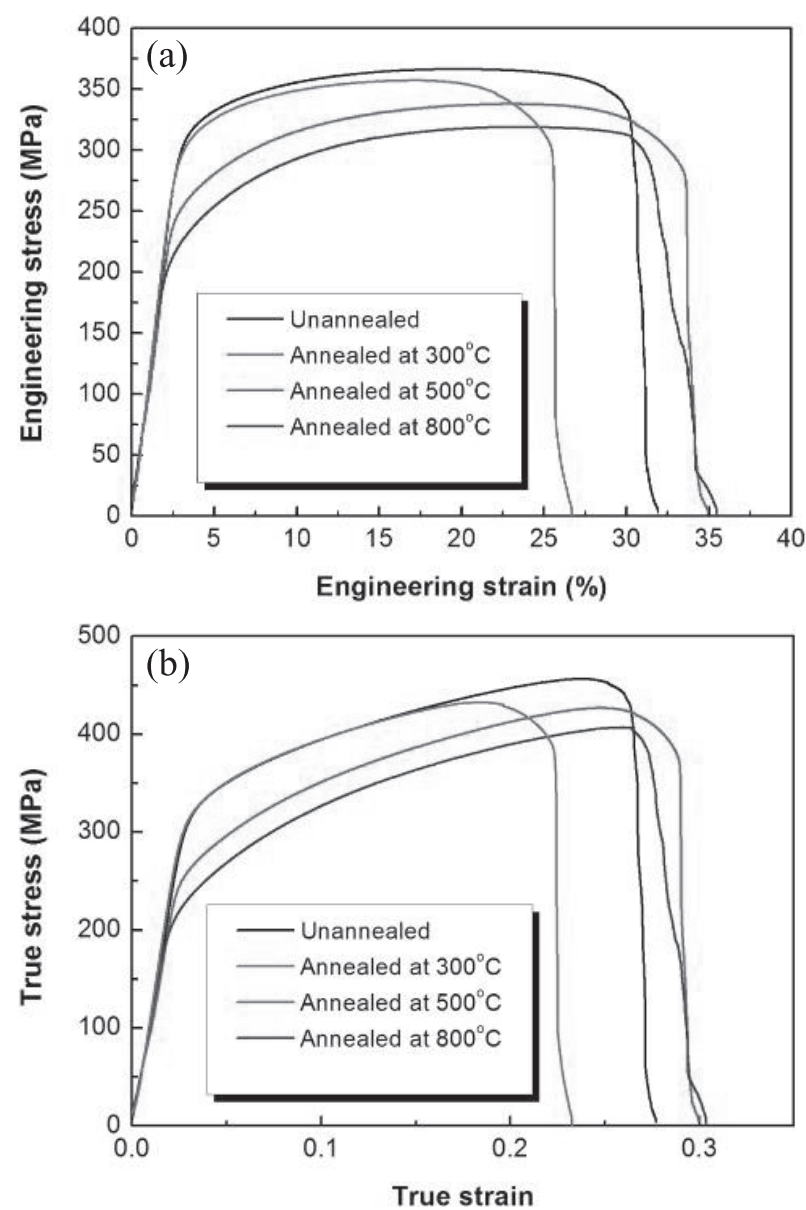

Fig. 8 Engineering stress-strain curves (a) and true stress-strain curves (b) of the $\mathrm{Cu} / \mathrm{Ti}$ composites processed by one ARB cycle and the subsequent annealing.

fabricated by ARB process. The macroscopic lamellar structures, mechanical properties and microstructures of the composites were investigated. The mechanical stability of the composites after annealing was also evaluated. The following conclusions can be drawn:

(1) During the co-deformation of the $\mathrm{Cu} / \mathrm{Ti}$ multilayers, $\mathrm{Cu}$ and $\mathrm{Ti}$ layers were well bonded. With the increasing number of ARB cycles, Ti layers with relatively large strength and work hardening ability started to neck, fracture and even segregate within the $\mathrm{Cu}$ matrix, which resulted in the most prominent feature of some lenticular nodules produced in the microstructure. This was attributed to the activation of shear bands across the multiple metal layers. At larger ARB cycles, the distribution of small fragmentations of Ti inside the $\mathrm{Cu}$ matrix was homogeneous.

(2) The yield strength and the ultimate strength of the $\mathrm{Cu} /$ Ti composites increased with the increasing ARB cycles, while the maximum elongation decreased gradually. After the fourth cycle, the maximum tensile strength reached $395 \mathrm{MPa}$, which was around 0.5 times higher than that of the primary copper, and was only slightly lower compared to the primary Ti. The maximum elongation of the ARBed composites was 0.55 times higher than that of the annealed pure copper.

(3) For the Ti layers within the composites, the hardness increased with increasing ARB numbers from 1 to 3 cycles and a small decrease of hardness was found after the fourth 
cycle. For the $\mathrm{Cu}$ layers, however, during the whole period of $\mathrm{ARB}$ the hardness only shows a minor increase. Therefore, the increase of strength in the composites during the ARB processing mainly resulted from the reinforcement of the Ti layers.

(4) In the Ti layers of the composites, there existed two characteristic morphologies: the intense dislocation tangles/ networks and the sub-grain cells with a mean size less than $200 \mathrm{~nm}$. For the $\mathrm{Cu}$ layers, a considerable amount of annealing twins together with significantly low dislocation density was the prominent feature. The mixed microstructures in the both constituents lead to the limited increase of strength and the retained ductility of the composites during ARB.

(5) Compared with the composites without annealing or with annealing at $300^{\circ} \mathrm{C}$, the $\mathrm{Cu}$ - $\mathrm{Ti}$ interfaces in the $500^{\circ} \mathrm{C}$ and $800^{\circ} \mathrm{C}$ annealed composites were much flatter after cold rolling, indicating that annealing suppressed the formation of shear bands. Although the composites experienced high-temperature annealing, high ductility and considerable strength were retained, indicating the excellent mechanical stability of the composites after annealing.

\section{Acknowledgments}

This work was financially supported by the National Natural Science Foundation of China (No. 51571057), the Program for New Century Excellent Talents in University (No. NCET-13-0104) and the joint open fund supported by Liaoning Natural Science Foundation and Shenyang National Laboratory for Materials Science (No. 2015021003).

\section{REFERENCES}

1) N.V. Govindaraj, J.G. Frydendahl and B. Holmdal: Mater. Des. 52 (2013) 905-915.

2) B.A. Movchan and F.D. Lemkey: Mater. Sci. Eng. A 224 (1997) 13645.

3) M. Eizadjou, A.K. Talachi, H.D. Manesh, H. S. Shahabi H and K. Janghorban: Compos. Sci. Technol. 68 (2008) 2003-2009.

4) J. McKeown, A. Misra, H. Kung, R.G. Hoagland and M. Nastasi: Scr. Mater. 46 (2002) 593-598.

5) S. Petrović, D. Peruško, M. Mitrić, J. Kovac, G. Dražić, B. Gaković, K.P. Homewood and M. Milosavljević: Intermetallics 25 (2012) 27-33.

6) S.J. Zheng, J. Wang, J.S. Carpenter, W.M. Mook, P.O. Dickerson, N.A. Mara and I.J. Beyerlein: Acta Mater. 79 (2014) 282-291.

7) G.H. Min, J.M. Lee, S.B. Kang and H.W. Kim: Mater. Lett. 60 (2006) 3255-3259.

8) M. Alizadeh and M. Samiei: Mater. Des. 56 (2014) 680-684.

9) L. Jiang, M.T. Pérez-Prado, P.A. Gruber, E. Arzt, O.A. Ruano and M.E. Kassner: Acta Mater. 56 (2008) 1228-1242.

10) M.P. Liu, S.C. Sun, H.J. Roven, Y.D. Yu, Z. Zhang, M. Murashkin and
R.Z. Valiev: Trans. Nonferrous Met. Soc. China 22 (2012) 1810-1816.

11) C.A. Davy, K. Han, P.N. Kalu and S.T. Bole: IEEE Trans. Appl. Supercond. 18 (2008) 560-563.

12) S. Ohsaki, S. Kato, N. Tsuji, T. Ohkubo and K. Hono: Acta Mater. 55 (2007) 2885-2895.

13) N. Jia, F. Roters, P. Eisenlohr, D. Raabe and X. Zhao: Acta Mater. 61 (2013) 4591-4606.

14) L.F. Zeng, R. Gao, Q.F. Fang, X.P. Wang, Z.M. Xie, S. Miao, T. Hao and T. Zhang: Acta Mater. 110 (2016) 341-351.

15) Y.M. Hwang, H.H. Hsu and H.J. Lee: Int. J. Mach. Tools Manuf. 36 (1996) 47-62.

16) Y.N. Wang and J.C. Huang: Mater. Chem. Phys. 81 (2003) 11-26.

17) S.L. Semiatin, P.A. Kobryn, E.D. Roush, D.U. Furrer, T.E. Howson, R.R. Boyer and D.J. Chellman: Metall. Mater. Trans., A 32 (2001) 1801-1811.

18) D. Terada, S. Inoue and N. Tsuji: J. Mater. Sci. 42 (2007) 1673-1681.

19) K. Wu, H. Chang, E. Maawad, W.M. Gan, H.G. Brokmeier and M.Y. Zheng: Mater. Sci. Eng. A 527 (2010) 3073-3078.

20) Q.M. Wei, X.Y. Liu and A. Misra: Appl. Phys. Lett. 98 (2011) 111907.

21) M. Gupta, S.M. Amir, A. Gupta and J. Stahn: Appl. Phys. Lett. 98 (2011) 101912.

22) W.Z. Han, J.S. Carpenter, J. Wang, I.J. Beyerlein and N.A. Mara: Appl. Phys. Lett. 100 (2012) 011911.

23) J.S. Carpenter, S.C. Vogel, J.E. LeDonne, D.L. Hammon, I.J. Beyerlein and N.A. Mara: Acta Mater. 60 (2012) 1576-86.

24) V. Yousefi Mehr, M.R. Toroghinejad and A. Rezaeian: Mater. Sci. Eng. A 601 (2014) 40-47.

25) B.L. Hansen, J.S. Carpenter, S.D. Sintay, C.A. Bronkhorst, R.J. McCabe, J.R. Mayeur, H.M. Mourad, I.J. Beyerlein and N.A. Mara: Int. J. Plast. 49 (2013) 71-84.

26) H.S. Liu, B. Zhang and G.P. Zhang: J. Mater. Sci. Technol. 27 (2011) $15-21$.

27) J.Y. Zhang, S. Lei, Y. Liu, J.J. Niu, Y. Chen, G. Liu, X. Zhang and J. Sun: Acta Mater. 60 (2012) 1610-1622.

28) R.N. Dehsorkhi, F. Qods and M. Tajally: Mater. Sci. Eng. A 530 (2011) 63-72.

29) L. Ghalandari, M.M. Mahdavian, M. Reihanian and M. Mahmoudiniya: Mater. Sci. Eng. A 661 (2016) 179-186.

30) A. Mozaffari, H.D. Manesh and K. Janghorban: J. Alloy. Compd. 489 (2010) 103-109.

31) D.K. Yang, P. Cizek, P. Hodgson and C. Wen: Scr. Mater. 62 (2010) 321-324.

32) P. Qu, L.M. Zhou and V.L. Acoff: Mater. Charact. 107 (2015) 367-375

33) D.Z. Wang, B.Z. Yin, A.K. Sun, X.L. Li, C.K. Qi and B.H. Duan: J. Alloy. Compd. 674 (2016) 347-352.

34) Y.M. Wang and E. Ma: Acta Mater. 52 (2004) 1699-1709.

35) N. Tsuji, Y. Saito, S.H. Lee and Y. Minamino: Adv. Eng. Mater. 5 (2003) 338-344.

36) Y. Saito, H. Utsunomiya, N. Tsuji and T. Sakai: Acta Mater. 47 (1999) 579-583.

37) Z.P. Xing, S.B. Kang and H.W. Kim: J. Mater. Sci. 37 (2002) 717-722.

38) F.H. Kavarana, K.S. Ravichandrana and S.S. Sahay: Scr. Mater. 42 (2000) 947-954.

39) N. Jia, R.L. Peng, Y.D. Wang, S. Johansson and P.K. Liaw: Acta Mater. 56 (2008) 782-793.

40) M. Ardeljan, M. Knezevic, T. Nizolek, I.J. Beyerlein, N.A. Mara and T.M. Pollock: Int. J. Plast. 74 (2015) 35-57. 